\title{
Infra-red photothermal thermography: A tool of assistance for the restoration of murals paintings?
}

\author{
By Jean Charles Candoré*, Gabriela Szatanik**, J.L Bodnar*, Vincent Detalle**, Philippe Grossel ${ }^{*}$
}

*Laboratoire d'Energétique et d'Optique, UFR Sciences Exactes et Naturelles, BP 1039, 51687 Reims cedex 02, France

${ }^{* *}$ Restauratrice du patrimoine, 6 allée Pasteur, 78330 Fontenay le Fleury, France

*** Laboratoire de recherche des monuments historiques, 29 avenue du Paris, 77420 Champs sur Marne, France

\section{Abstract}

This work deals with the examination of artwork by photothermal radiometry. It was initiated at the time of the restoration of a florentine XIV century mural painting, the Saint Christopher of the Louvre Museum.

The aim of this work is to evaluate the possibilities of photothermal radiometry concerning detection of deterioration of internal structure of painting, non visible on surface. The study concentrated on the detection of separations of coating and the existing air voids between the various layers of the support, which create zones of brittleness which often requires an intervention of consolidation.

The photothermal analysis was initially carried out on a counterpart of the fresco. In a second time it is the Saint Christopher itself which was controlled. The results obtained clearly show the possibility of detecting defects located in such works of art. The correlation between the information collected by photothermal analysis and traditional acoustic sounding was demonstrated and finally shows the interest to associate these two methods of non-destructive testing.

\section{Introduction}

Delamination and air voids in renders are among the main sources of deterioration of mural paintings. Those decays are particularly dangerous because they are almost non visible (underlying), but they can induce falls of parts of the artistic composition depending on their nature and the affected surface.

The traditional technique used by the restorers to localize delaminated areas is acoustic sounding. It consists in a systematic slight knocking of the painted surface with one hand, when the other hand stays in contact with the surface. The vibration induced by the knocking is then perceived both by hear and touch and allows an experienced restorer to determine the extent of the decay on the basis of an empirical evaluation of the propagation of the vibration.

This technique which is qualitative is very simple and does not necessitate any specific equipment, but the results are not very precise and their quality depends a lot on the skills of the restorer. For example, the thickness or the depth of an air void cannot be detected when they represent valuable information for the restorer to evaluate the real state of decay of the mural painting and as a consequence is a key point for the choice of a suitable restoration technique.

Moreover, a contact with the mural painting, more or less long and powerful, is needed. This action can be hazardous if the painting is powdering or weakened by scaling (as it was the case for the "Saint Christopher" of the Campana collection of the Louvre museum, before its restoration); or if the render is too thin (it then can collapse if the knocking is too powerful).

Finally, when the surfaces painted are wide, this operation can be long and laborious. [1-2].

As infrared photothermal thermography has been successfully tested to localize and characterize decays such as delamination or cracking in several materials [3-23], it seemed interesting to evaluate its possible application in the field of historical monuments restoration, and in the specific case of mural paintings as a complementary method of the empirical acoustic technique.

Infrared photothermal thermography is a non-contact and quantitative technique which allows rapid large surface examinations.

In this study, we evaluated the performances of the technique in terms of precise localization and cartography of decays of the internal structure of mural paintings, invisible to the naked eye. The tests were focused on the detection of renders detachment and air voids situated in the underlying layers of the render, which are decays often generating weakened areas necessitating later consolidation.

At first the tests were performed on a fresco replica, and then the technique was applied to the real "Saint-Christopher" wall painting which had at the same been time traditionally knocked.

Our presentation is divided into three parts:

Initially we present the experimental device used for the study.

Then we have the results obtained on a partial counterpart with defects, of the Saint Christopher.

Finally we have the results obtained on the Saint Christopher.

\section{The experimental device used for the study}

Generally, the device used for photothermal radiometry is always made of a system of three principal elements: an excitation source which transmits heat to the examined object, tools of detection and visualization of the thermal signal obtained and a tool of data filing and processing.

In our study, as source of excitation, we implemented various devices (we did not know a priori the thermal behavior of the Saint Christopher) : A visible halogen lamp, an infra-red lamp and a hair dryer. The first two excitation sources 
allowed to cover two spectral excitation bands. The third excitation source enabled us to be free from the optical problems of energy absorption.

As tools for detection, we used two cameras of thermography. The first one is a AGA Thermovision 780 camera, available at the LRMH and transportable for the in situ examination of paintings. This camera was used for the examination of the Saint Christopher. The second one, more recent, is a JADE 2 camera, lent by the Ecole Nationale des Arts et Métiers of Châlons en Champagne (school specialized in mechanical and industrial engineering), was only available in their research laboratory. It has the advantage of being state-of-the-art technology and entirely controlled by computer (in preprocessing and postprocessing). It presents the drawback of not being mobile (problems of insurances) and thus usable for the analysis of the fresco itself (laid out for restoration at the National Institute of the heritage located at Saint Denis la Plaine).

\section{Analysis of the counterpart of the fresco}

Before analyzing the Saint Christopher, photothermal method and experimental protocol were at first tested on a partial replica of the fresco. This replica is presented on figure 1. It was made of a mixture of lime and sand. Four defects were introduced in the replica (air voids, figure 2). They are at the four corners of the replica. The first defect is on the top left corner, it is $3 \mathrm{~mm}$ deep and its thickness is $3 \mathrm{~mm}$. The defect on the top right corner is $5 \mathrm{~mm}$ deep and between $3 \mathrm{~mm}$ and $10 \mathrm{~mm}$ thick. The defect on the bottom left corner is $3 \mathrm{~mm}$ deep and $5 \mathrm{~mm}$ thick, and the last defect on the bottom right corner is $5 \mathrm{~mm}$ thick and varied between $3 \mathrm{~mm}$ and $10 \mathrm{~mm}$ in depth. The front face of the fresco was painted according to the technique of primitive Italian and reproducing the infant Jesus.

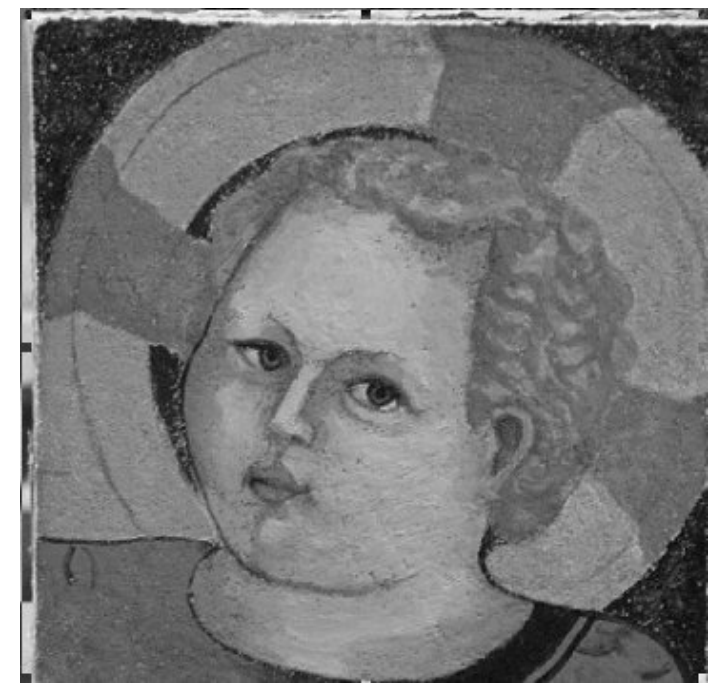

Fig.1. : the studied replica

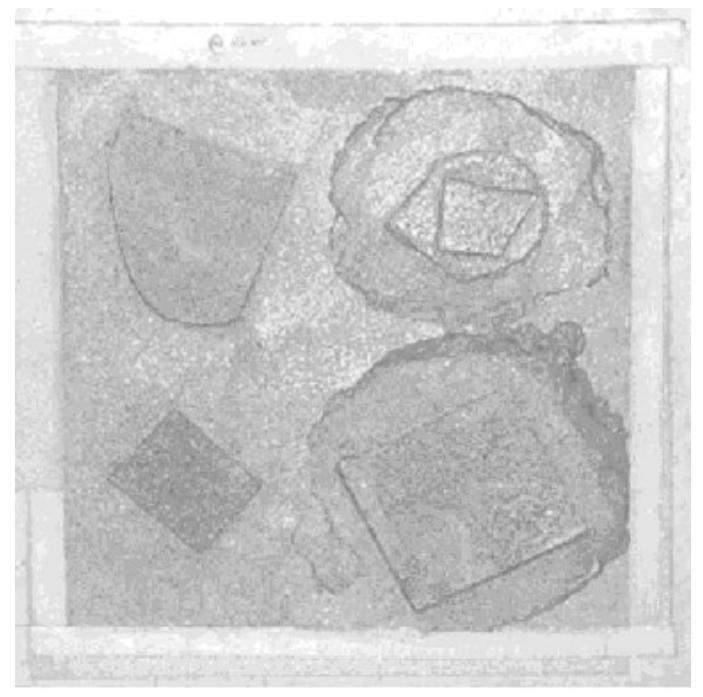

Fig. 2. : localization of defects in the replica

The type of excitation used for the study of the replica is a Heavyside of 120 seconds' duration. The exiting source used is an infra-red lamp of $250 \mathrm{~W}$ (it gave the best results among the three types of excitation considered). The camera used for the study was the JADE 2. The acquisition frequency was 25 frames per second. The time of observation was 300 seconds. The results obtained are presented on figures 3 to 6 . Figure 3 represents the photothermal image obtained 


\section{http://dx.doi.org/10.21611/qirt.2006.037}

before excitation. No defect is visible at this stage of the study. Figure 4 represents the photothermal image obtained two seconds after the end of the phase of excitation. It reveals clearly defects which are near the surface. Finally the thermal signature of the four defects are visible on figures 5 and 6 were obtained at 120 and 190 seconds after the end of the excitation.

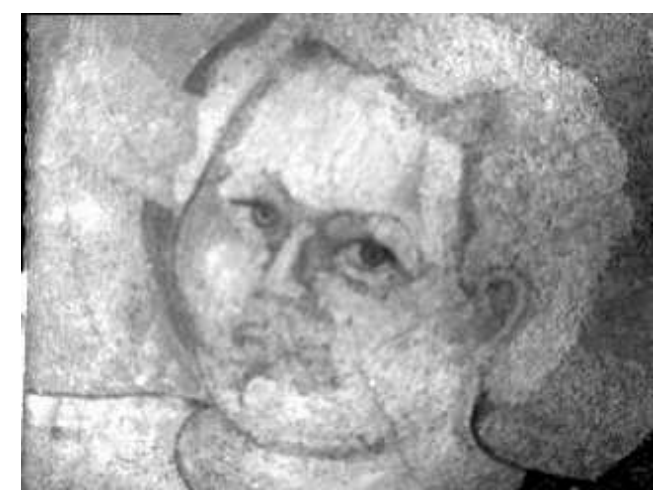

Fig. 3. : photothermal Image of replica before photothermal analysis

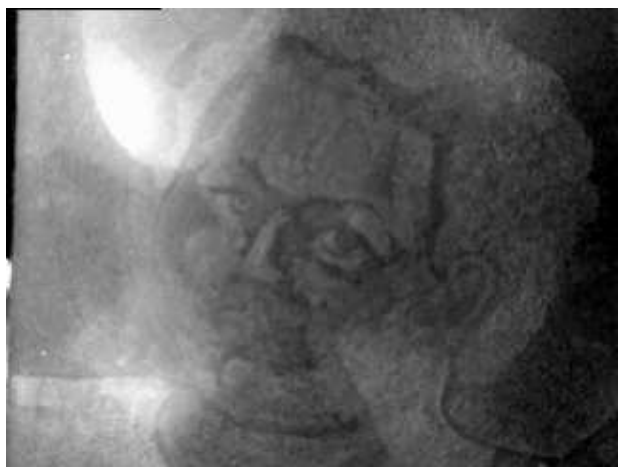

Fig. 4. :Photothermal Image of replica 2 seconds after the end of excitation

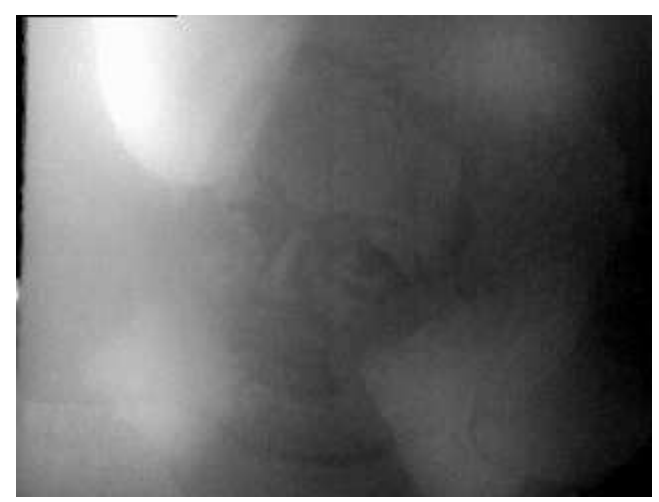

Fig. 5. : Photothermal Image of replica 120 seconds after the end of excitation

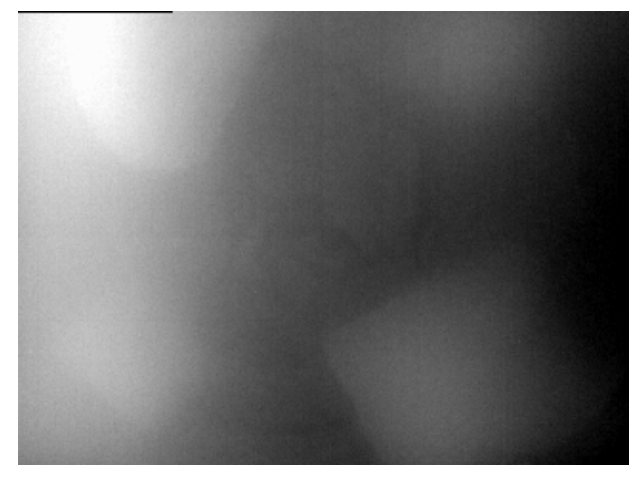

Fig. 6. : Photothermal Image of replica 190 seconds after the end of excitation 


\section{http://dx.doi.org/10.21611/qirt.2006.037}

\section{Analysis of the Saint Christopher}

Tests performed on the replica were satisfactory, so we decided to study the Saint Christopher, a fresco of the fourteenth century. This fresco presented on figure 7, represents Saint Christopher carrying the infant Jesus. This work is attributed to Tommaso del Mazza and was created between 1385 and 1390. Its dimensions are a $85.8 \mathrm{~cm}$ high and 74 $\mathrm{cm}$ wide. It forms part of the Campana collection of the Louvre museum [24].

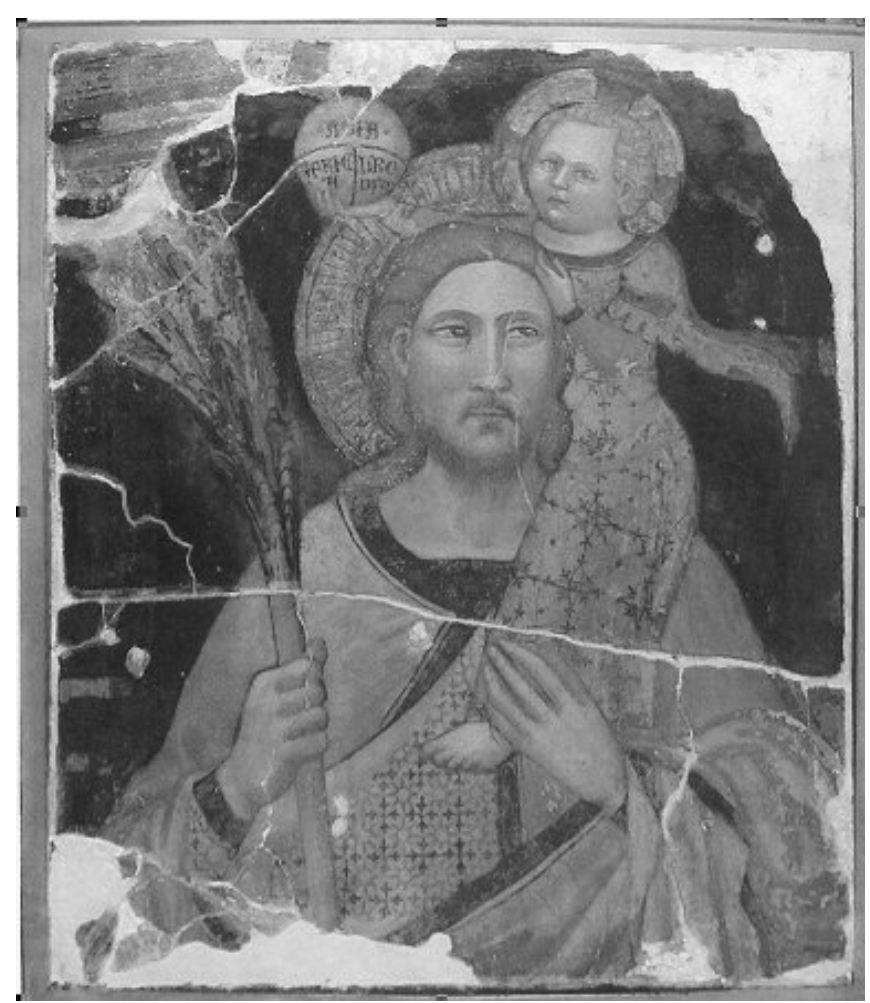

Fig. 7. : The studied fresco

For the study of this artwork, we used an experimental device composed of two halogens lamps of 800 Watts. These lamps provide a heating more homogeneous on the analyzed area than the infrared lamps. The detection was performed by the Thermovision camera of LRMH. Sources and camera were placed at a distance of 1.50 meters from the fresco (figures 8,9 ). The time of heating was 6 minutes. Finally, the fresco was analyzed area by area to obtain a higher optic resolution for each picture.

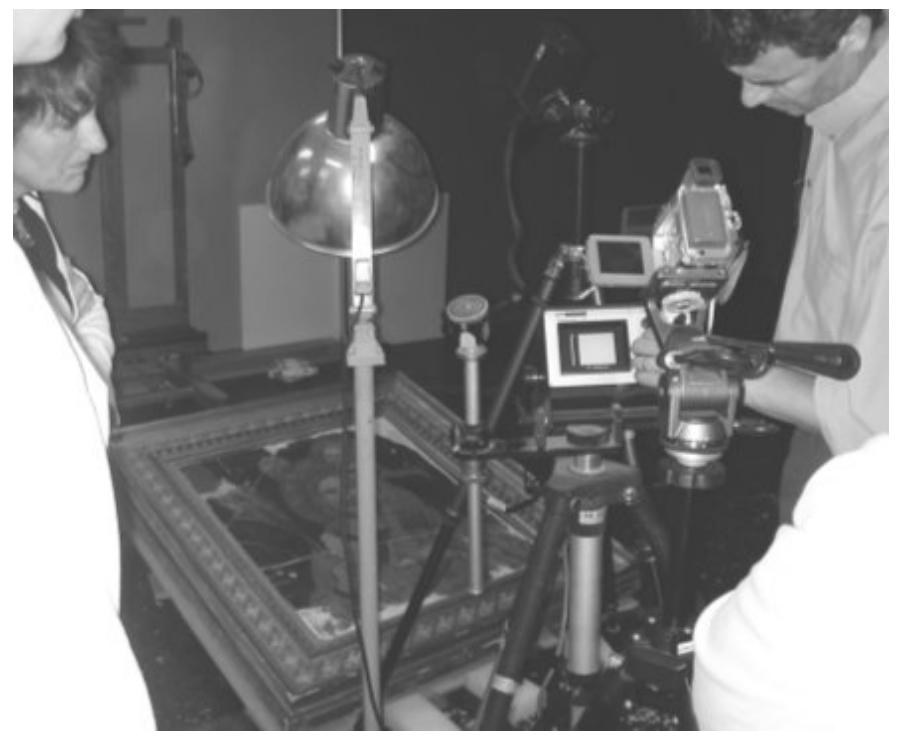

Fig. 8. : Non destructive testing of the Saint Christopher by infrared thermography : The experimental device 


\section{http://dx.doi.org/10.21611/qirt.2006.037}

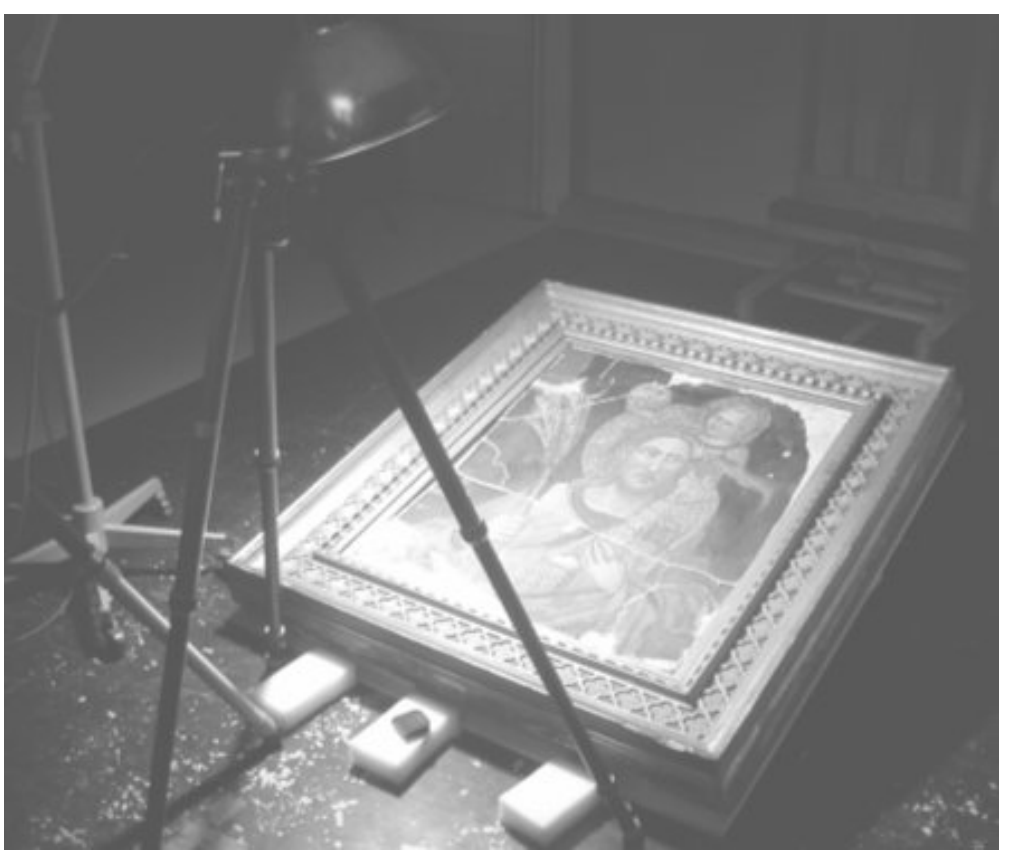

Fig. 9. : Analyzing the Saint Christopher

Some results obtained are presented on figures 10 to 13. On figure 11, the area analyzed was the surrounding hand of the Saint Christopher. This figure reveals a dark spot, near the right hand of the Saint Christopher during the cooling phase of the analysis. This spot almost appeared one minute after the extinction of the lamps. It continued to darken up to 2 minutes 30 seconds after the beginning of the cooling process. After 4 minutes, its signal started to grow blurred. This signature seems to indicate that this air pocket is rather deep (with our different analyses, we estimate it to be roughly to $6-10 \mathrm{~mm}$ in depth and 5 to $10 \mathrm{~mm}$ thick). To confirm this result, we realized an acoustic sounding of the hand (figure 14). Sonority recorded is quite characteristic of an important air void, which confirms the results obtained by photothermal radiometry. On figures 12 and 13 it is the area surrounding the right shoulder of the Saint Christopher which is analyzed. The defect detected by thermography was also detected by acoustic sounding.

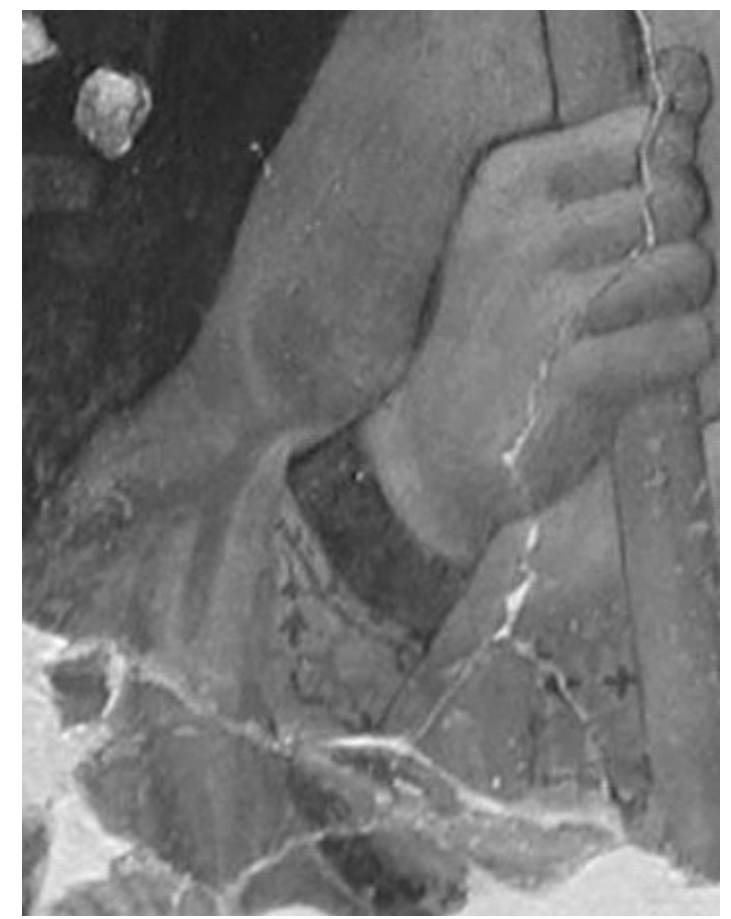

Fig. 10. : Analysis of Saint Christopher's hand 
http://dx.doi.org/10.21611/qirt.2006.037

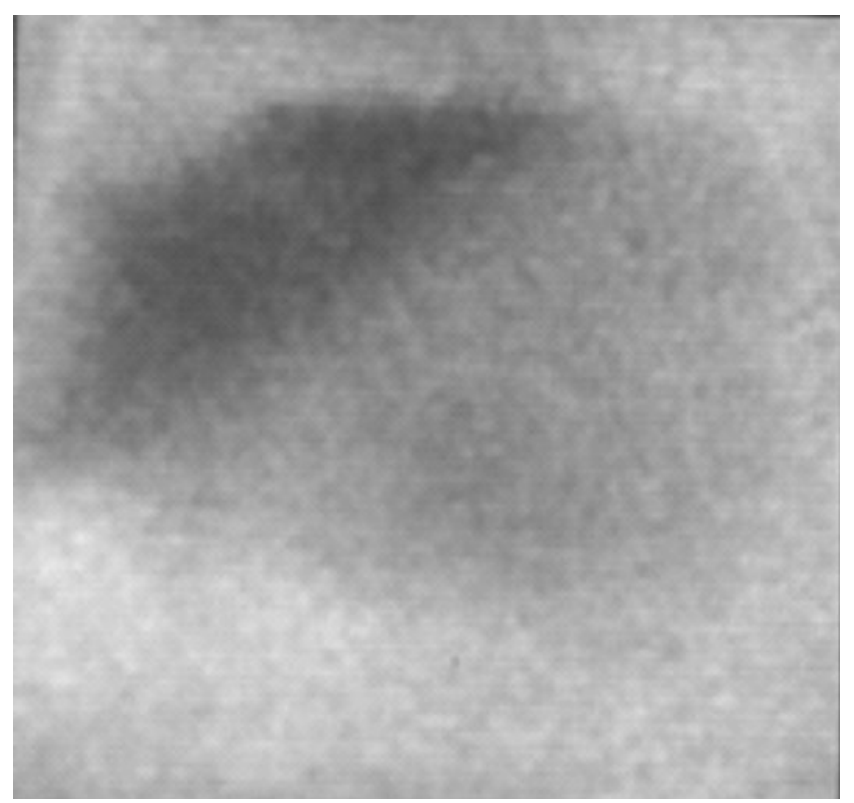

Fig. 11. : Image of Saint Christopher's hand, 2 $\mathrm{mn}$ and $10 \mathrm{~s}$ after the end of the heating period.

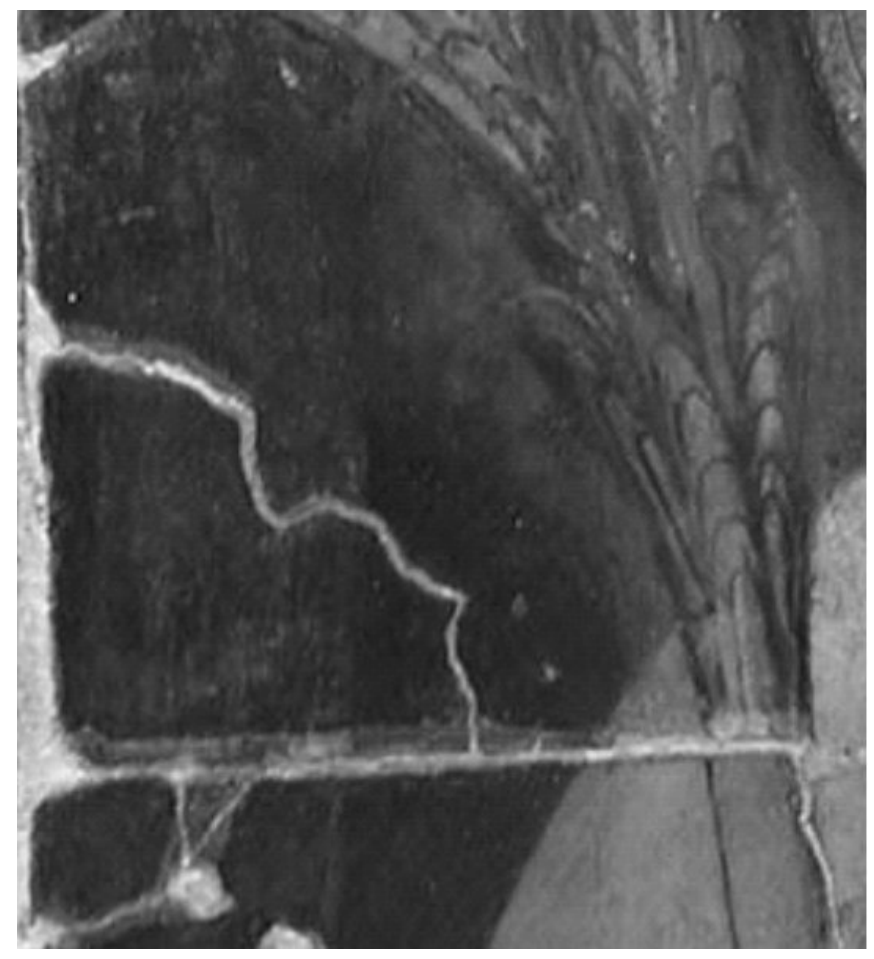

Fig. 12. : Analysis of Saint Christopher right shoulder 


\section{http://dx.doi.org/10.21611/qirt.2006.037}

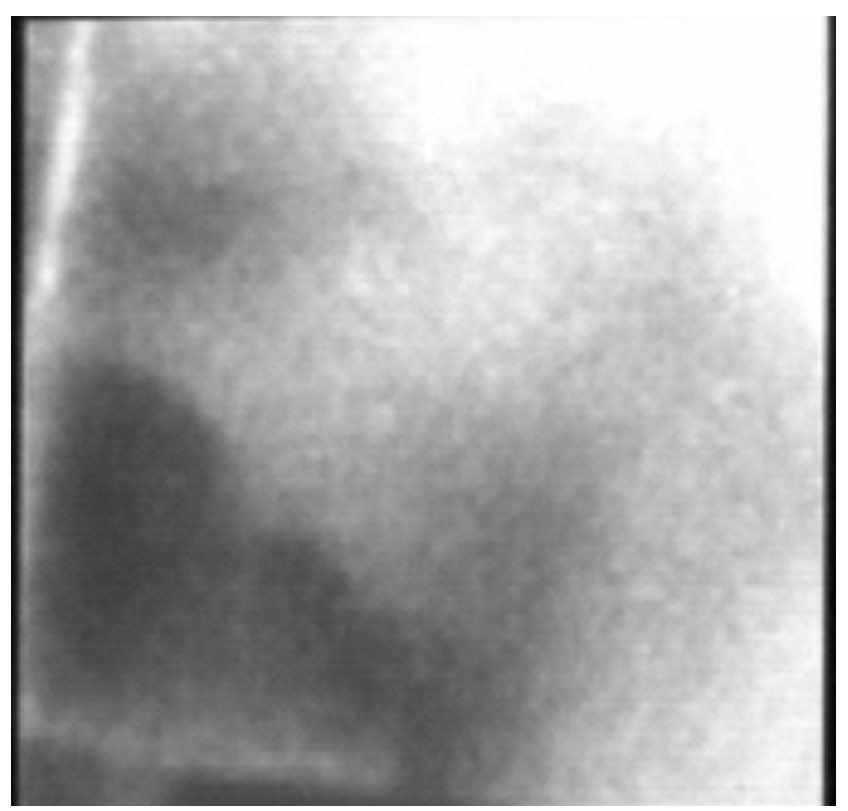

Fig. 13. : Image of Saint Christopher's right shoulder, 2 $\mathrm{mn}$ and $10 \mathrm{~s}$ after the end of the heating period.

On figures 15 and 16, we have compared results obtained by photothermal radiometry (with a heating period reduced to 2 minutes) with results obtained by acoustic sounding (figure 14). It was realized on the whole fresco.

On the one hand, we notice that the characteristic signatures of visible defects by photothermal radiometry correspond to areas of detachment detected with the acoustic sounding method.

In addition, we notice, with our experimental parameters, we detect fewer air voids by photothermal radiometry than acoustic sounding.

Experimentally, defects detected at the same time by photothermal radiometry had the same sonority by acoustic sounding. It confirms they should be located at the same depth. A dimensional characterization of the defects seems to be possible with the photothermal analysis, which is more difficult by acoustic method.

Finally, the data acquisition is much faster by photothermal radiometry than by acoustic sounding.

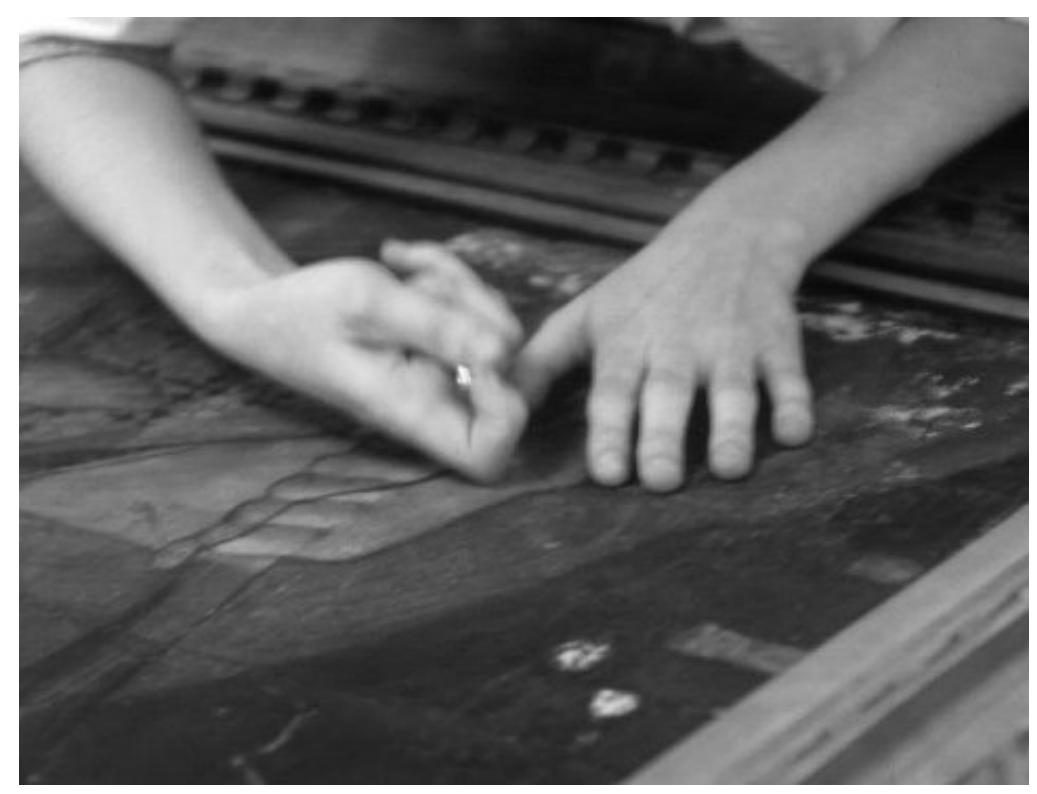

Fig. 14. : Acoustic sounding of Saint Christopher 
http://dx.doi.org/10.21611/qirt.2006.037

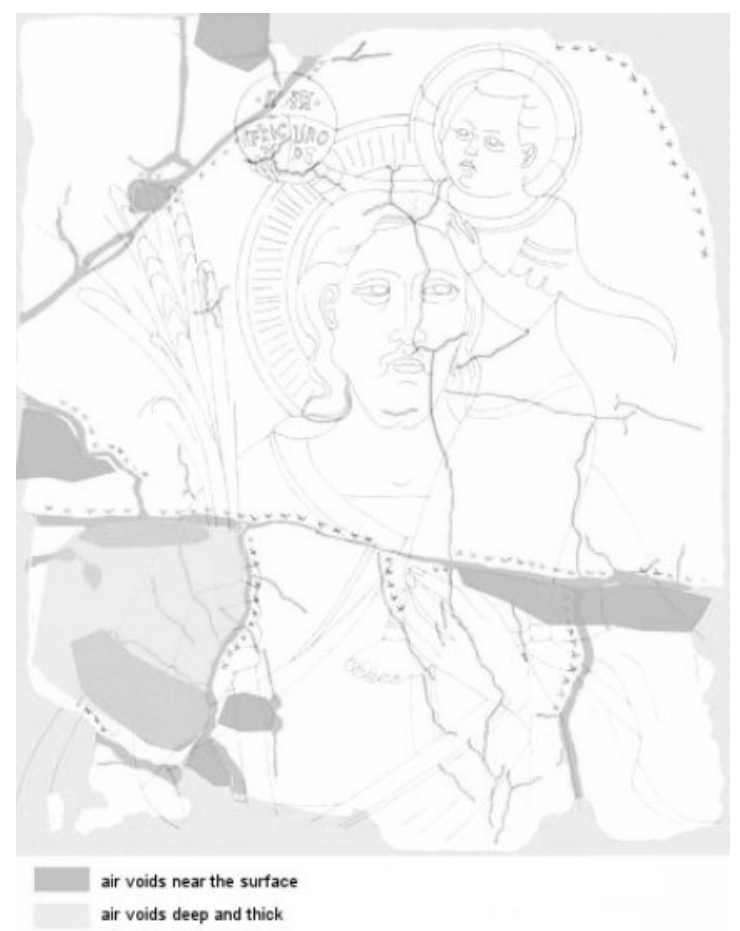

Fig. 15. : Results obtained by photothermal radiometry

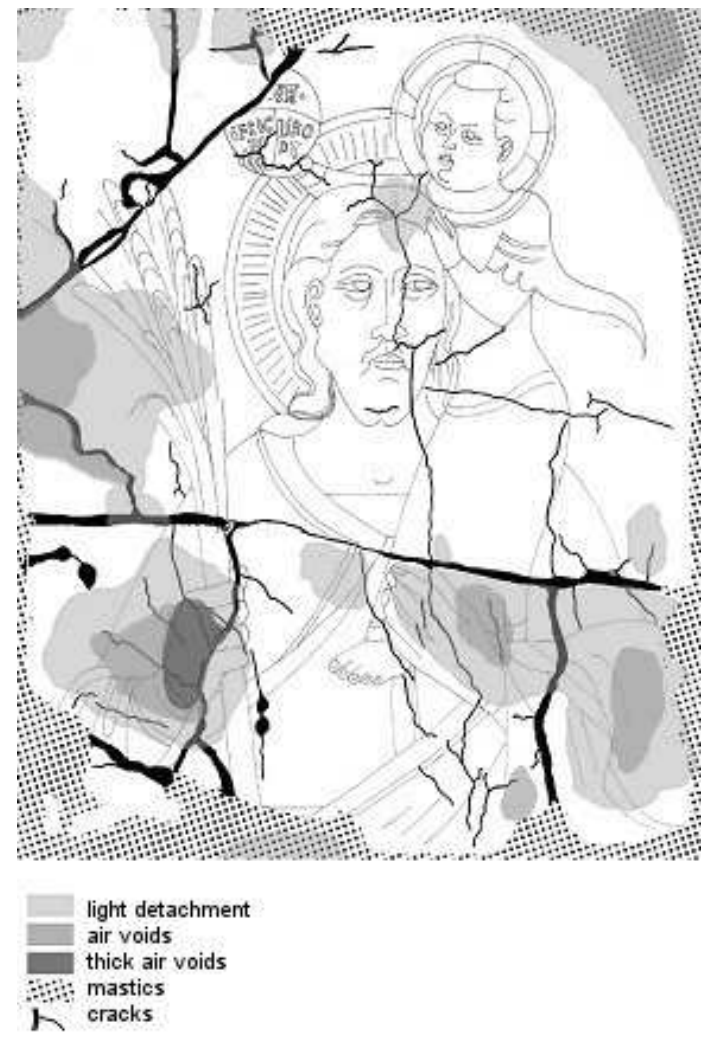

Fig. 16. : Results obtained by acoustic sounding 


\section{Conclusion}

In this work, we studied the possibilities of photothermal radiometry concerning detection of defects in works of art (the Saint Christopher).

First, tests were performed on a partial replica of the fresco that contains four defects with different geometric dimensions and located at different depths. They were detected by photothermal radiometry, the closer the defect from the surface, the earlier it was detected.

Then, we studied the Saint Christopher. The results obtained confirm the possibility of detecting air voids in the internal structure of the work of art. The method is faster, less intrusive and more objective than acoustic sounding. In addition, the photothermal method seems capable of giving in depth information of the defect location. Lastly, under our experimental condition, the photothermal method seems to allow detection of a smaller number of defects than the traditional acoustic method.

These different results show that photothermal radiometry and the traditional acoustic sounding are complementary methods to analyze frescoes. They also show it would be interesting to optimize the experimental conditions of the photothermal method (random analysis, inverse problems,...[19, 22, 23]), to define their real limits. Plus they still show that complementary studies should be undertaken to lead to measurements of depth of defects. They finally show that photothermic radiometry can be used successfully to help with the restoration of works of art.

\section{References}

[1] G. Szatanick : Etude et restauration d'une peinture murale représentant Saint Christophe, thèse de l'INP, sept 2004.

[2] Ibid, p30.

[3] J.L Bodnar, C. Menu, M. Egée, M. Pigeon, C. Bourg, A. Le Blanc : Modelisation of crack detection in a coated metal by photothermal radiometry. Proceeding of the $10^{\text {th }}$ international conférence on NDE in the nuclear and pressure vessel industries, june, 4-7, 1990 Glasgow, Scotland.

[4] J.L Bodnar, C. Menu, M. Egée, M. Pigeon, A. Le Blanc : Détection de fissures par méthode photothermique. Actes du congrès de la Société Française de Thermique, 20-21 mai 1992, Sophia-Antipolis.

[5] J.L Bodnar, C. Menu, M. Egée, M. Pigeon, A. Le Blanc : Wear cracks detection by photothermal radiometry. Wear, 162 - 164 (1993) $590-592$.

[6] J.L Bodnar, C. Menu, M. Egée, M. Pigeon, A. Le Blanc : Détection de fissures par radiométrie photothermique sous excitation sinusoïdale Revue pratique de Contrôle Industriel, spécial CND, mars 1993, n¹79, pp 50 -55.

[7] J.L Bodnar, M. Egée, C. Menu, R. Besnard, A. Le Blanc, J.Y. Sellier : Détection de fissures par sonde photothermique mobile. Actes du colloque de la Société Française de Thermique, 25-26 mai 1993, Pau.

[8] J.L Bodnar: Radiométrie photothermique appliquée à la détection et à la caractérisation de fissures. Thèse de doctorat, 21 septembre 1993.

[9] J.L Bodnar, M. Egée, C. Menu, R. Besnard, A. Le Blanc, J.Y. Sellier : Cracks Détection by photothermal mobile probe : theory and experimentation. Proceeding of the 12th international conference and exhibits of NDE in nuclear and pressure vessel industries, 10-13 octobre 1993, Philadelphie, USA.

[10] J.L Bodnar, M. Egée, C. Menu, R. Besnard, A. Le Blanc, J.Y. Sellier : Cracks Détection by a moving photothermal probe. Journal de Physique IV, volume 4, juillet 1994, pp $591-594$.

[11] J.L Bodnar, M. Egée, C. Menu, R. Besnard, A. Le Blanc, P.Morisseau : Fast cracks study by photothermal radiometry. Proceeding of the $6^{\text {th }}$ conférence on Non Destructive Testing, 24 - 28 Octobre 1994, Nice.

[12] J.L Bodnar, M. Egée : Wear cracks characterization by photothermal radiometry. Wear volume 196, 1996,54 - 59.

[13] D. Manuel, J.L Bodnar : Tomographie par radiométrie photothermique : Application à la caractérisation de défauts subsurfaciques Actes du colloque de la Société Française de Thermique, 20-22 mai 1997, Toulouse.

[14] L. Durville, J.L Bodnar, Y. Gillet : Parametric analysis applied to photothermal radiometry under random excitation. Proceeding of the $X$ conference on photoacoustic and photothermal phenomena, Rome, 23 -27 aout 1998

[15] J.L Bodnar : Imagerie thermique, le contrôle non destructif des matériaux, thermogram' 2001, 18 oct 2001, Senart.

[16] J.L. Bodnar : La radiométrie photothermique aléatoire : une méthode de contrôle non destructif d'avenir ? Exposition de physique, cycle de conférences "physique, recherche industrie 2001", 24 oct 2001, Paris.

[17] F. Jouart, A Boutemy, J.L Bodnar: Approche des possibilités de la radiometrie photothermique aléatoire en matière de détection de défauts. Actes du congrès de la Société Française de Thermique $3-6$ juin 2002, Vittel.

[18] F. Jouart, F. Pierron, J. Schlosser, J.L. Bodnar, A. Durocher: Contrôle non destructif d'éléments face au plasma du Tokamak Tore Supra par thermographie infrarouge stimulée. Actes du colloque "mesures optiques pour l'industrie", 1822 nov 2002, Saint Aubin de Medoc

[19] J.L Bodnar : Contrôle non destructif par radiométrie photothermique aléatoire. thermogram' 2003, nov 2003, Senart.

[20] J.L Bodnar : Contrôle non destructif par techniques infrarouges. Colloque CMOI, nov 2003, Belfort.

[21] G.Brun et et J.L.Bodnar : Caractérisation de défaut par radiométrie photothermique impulsionnelle. Actes du colloque "mesures optiques pour l'industrie", 15-19 nov 2004, Saint Etienne.

[22] J.L.Battaglia et J.L Bodnar : Thermophysical parameters estimation using the system identification approach, Proccedings of the Eurotherm Winter School, METTI 2005, Aussois, January 16-21, 2005.

[23] P. Vasseur, J.L Bodnar, S. Brahim et P. Grossel : Caractérisation de défauts par radiométrie photothermique aléatoire. Actes du congrès de la Société Française de Thermique 30 mai -2 juin 2005, Reims

[24] Campana, 1858 